\title{
Nilai-Nilai Pendidikan Tata Busana dan Rias Srimpi Pandhelori dalam Perspektif Hermeneutik
}

\author{
Wenti Nuryani, Suminto A Sayuti, Dwi Siswoyo \\ Program Studi Ilmu Pendidikan Pascasarjana Universitas Negeri Yogyakarta \\ Jl. Colombo No 1, Depok, Caturtunggal, Kec. Depok, Kabupaten Sleman, Daerah Istimewa \\ Yogyakarta, 55281 \\ Tlp.087734147935, E-mail: wentinuryani@uny.ac.id
}

\begin{abstract}
This research was a descriptive qualitative research using a hermeneutic approach and was aimed at revealing the meaning of traditional symbols contained in Yogyakarta-style Srimpi Pandhelori dance costumes and makeup. The symbols in Srimpi Pandhelori costumes and makeup are the media that transform noble characters. It is closely related to the character building based on local genious. Therefore, this research is aimed at describing the symbols found in Srimpi Pandhelori dance as an absorption element of the noble character values. Every instrument in costumes and makeup represents local wisdom which is designed to be a medium of noble character education. The main data collection technique of the research was direct observation of Srimpi dance performances strengthened by records. The data were validated by using credibility techniques by doing 1). observation perseverance, 2). triangulation of methods and sources, 3). peer discussion, and 4). adequacy of references. The data analysis used in this research was a dialectical hermeneutics approach i.e. the approach where interpretation procedures to obtain meaning uses elements of analysis from Madisson called a normative method consisting of coherence, comprehensiveness, contextuality, penetration, and appropriateness. The results show that each instrument in costumes and make up of Srimpi Pandhelori dance pattern contains symbols. These symbols contain educational values, namely: the value of self-control education, the value of education about accuracy, the value of Godhead education.
\end{abstract}

Keywords: values, Srimpi Pandhelori, hermeneutic

\begin{abstract}
ABSTRAK
Penelitian ini merupakan penelitian deskriptif kualitatif dengan menggunakan pendekatan hermeneutik, bertujuan untuk mencari makna dari simbol-simbol tradisi dalam rias dan busana tari srimpi Pandhelori gaya Yogyakarta. Simbol-simbol dalam rias dan busana tari srimpi Pandhelori merupakan media mentransformasikan budi pekerti luhur. Hal tersebut berkaitan erat dengan pembagunan karakter yang didasarkan pada local genious. Oleh sebab itu dalam penelitian ini mencoba menguraikan simbol-simbol dalam tari Srimpi Pandhelori sebagai unsur serapan nilainilai budi pekerti luhur. Setiap insrumen dalam rias busana merupakan representasi kearifan lokal yang dimaksudkna menjadi media pendidikan budi pekerti luhur. Teknik pengumpulan data yang utama adalah pengamatan secara langsung pertunjukan tari Srimpi yang diperkuat dengan rekaman. Untuk keabsahan datanya menggunakan teknik kredibilitas yang dilakukan dengan cara: 1). ketekunan pengamatan, 2). trianggulasi metode dan sumber, 3). diskusi sejawat, 4). kecukupan referensi. Sementara analisis datanya menggunakan pendekatan hermeneutika dialektis, dimana prosedur penafsiran dalam rangka memperoleh makna menggunakan unsurunsur analisis dari Madisson yang disebutnya sebagai metode normatif, terdiri dari coherence, comprehensiveness, contextuality, penetration, appropriateness. Hasil penelitian menunjukan setiap instrumen dalam rias dan busana dalam tari Srimpi Pandhelori merupakan simbol. Dalam simbol tersebut mengandung nilai-nilai pendidikan yaitu: nilai pendidikan pengendalian diri, nilai pendidikan tentang kecermatan, nilai pendidikan Ketuhanan.
\end{abstract}

Kata Kunci: Nilai-Nilai Pendidikan, Srimpi Pandhelori, hermeneutik 


\section{PENDAHULUAN}

Seni tari berdasarkan bentuk garapnya dapat dibedakan menjadi dua, tari tradisional dan kreasi baru. Jenis tari tradisional masih dikelompokkan lagi menjadi tiga, yaitu tari primitif, tari klasik, dan tari kerakyatan (Soedarsono, 1996, hlm. 20). Tari primitif bersifat sangat sederhana, gerakannya menyerupai gerakan sehari-hari, yang terpenting di sini adalah keyakinan yang terletak di belakang tarian tersebut. Tari klasik, digunakan untuk menyebut kesenian yang berasal dari istana, karena mendapat pemeliharaan yang baik, dalam koreografinya, sehingga terciptalah standardisasi. Dalam hal ini Lindsay mengungkapkan:

tari klasik memiliki batasan-batasan formal, bentuk yang dapat dikenali, dan telah diatur menurut prinsip-prinsip formal. Dengan kata lain, kesenian istana terikat oleh aturan yang ketat, sedangkan tari kerakyatan, merupakan perkembangan dari zaman primitif, bentuk tarinya sangat sederhana dan kurang mengindahkan kaidah keindahan dan bentuk yang standar. Sementara itu tari kreasi baru adalah tari-tarian yang masih memiliki kaidah-kaidah bentuk yang mengacu pada seni tradisional, tetapi sudah tidak memiliki nilai simbolis serta nilai sakral. (Lindsay, 1991, hlm. 51)

Tari tradisi klasik memiliki berbagai varian, baik yang berbentuk tari tunggal, berpasangan maupunkelompok, Srimpiadalah salah satunya. Tarian ini lazim dibawakan oleh empat orang penari, dengan busana dan rias yang sama. Seperti yang dijelaskan oleh
Suryobrongto (1982, hlm. 17) bahwa “ ...beksa Srimpi cacah sekawan (4). Bab punika mendhet wewaton Dhawuh Dalem Hingkang Sinuwun Kanjeng Sultan Hagung Prabu Hanyokrokusumo, hingkang kawrat ing Babad Nitik, kaca 40. Pengagemipun dalah pahesipun sedaya wau dipun sami satunggal lan satunggalipun, tanpa wonten bedanipun" (tari Srimpi jumlahnya empat. Dalam hal ini selaras dengan sabda dan arahan dari Sultan Agung Hanyokrokusumo, yang ditulis dalam Babad Nitik halaman 40. Dalam hal busana dan riasnya semua dibuat sama, antara satu dengan lainnya tidak ada bedanya).

Tari Srimpi merupakan tarian peninggalan dari kerajaan Mataram. Sejak zaman kuno, tari Bedhaya maupun Srimpi sudah memiliki kedudukan yang istimewa di keraton Jawa dan tidak dapat disamakan dengan tarian yang lain karena sifatnya yang sakral, dan dianggap sebagai pusaka kerajaan. Berkaitan dengan hal ini Wardhana, (1981, hlm. 42) mengungkapkan "kategori sakral kita kenakan pertama-tama karena jenis tarian ini tidak sembarang waktu dipentaskan. Hanya pada keperluan tertentu di Keraton, yang merupakan pusat ritual Kejawen".

Srimpi merupakan suatu karya budaya yang mencerminkan ajaran luhur bagi nilai-nilai hidup manusiawi. Sudah tentu keberadaan tari Srimpi di beberapa istana selalu berkaitan erat dengan konsepsi hidup, konsepsi lingkungan, konsepsi budaya, konsepsi pendidikan, konsepsi harapan, ujubujub tertentu, bahkan kekuasaan itu sendiri. Di istana Yogyakarta diketahui bahwa Srimpi merupakan jenis penyajian tari putri yang 
bermakna bagi legitimasi kekuasaan raja. jaman pemerintahan HB I hingga HB VI penari Dalam hal ini kedudukan Srimpi tidak jauh beda dengan kedudukan Bedhaya maupun wayang wong (Pramutama, 1999, hlm. 1). Sejalan dengan hal ini Putraningsih (2016, hlm. 176) mengungkapkan bahwa tari-tarian keraton mengandung nilai-nilai filosofis yang tinggi. Nilai-nilai tersebut adalah, nilai etik, nilai estetika, sosial dan religius. Nilai- nilai ini bersumber pada budaya Jawa dengan segala kaidahnya yang diakui oleh masyarakat.

Gasiyah (2015, hlm. 396) mengatakan bahwa Bedhaya dan Srimpi memiliki tingkat kesakralan yang sama dengan pusaka atau benda-benda yang melambangkan kekuasaan raja yang berasal dari zaman Jawa Hindu. Kemunculan tari Srimpi berawal dari masa kejayaan Kerajaan Mataram saat Sultan Agung memerintah pada tahun 1613-1646. Tarian ini dianggap sakral karena hanya dipentaskan dalam lingkungan keraton untuk ritual kenegaraan sampai peringatan kenaikan tahta sultan. Pada tahun 1775 Kerajaan Mataram pecah menjadi Kasultanan Yogyakarta dan Kasunanan Surakarta. Perpecahan ini berimbas pada tari Srimpi sehingga terjadi perbedaan gerakan, walaupun inti dari tariannya masih sama (Gasiyah, 2015, hlm. 397).

Srimpi Pandhelori diciptakan pada masa pemerintahahan Hamengkubuwana (HB) VII pada tahun 1877-1921, dan hingga hari ini masih sering dipentaskan. Tentu saja dalam beberapa hal telah mengalami perubahan, yang sesuai perkembangan jaman. Perubahan dan perkembangan tersebut termasuk dalam hal elemen-elemen pendukung tari Srimpi, misalnya saja dalam hal tata busana. Pada Bedhaya maupun Srimpi mengenakan busana dodot/kemben, dengan rias paes ageng ataupun tanpa paes, dengan gelung bokor. Masuknya pengaruh Belanda mulai masa pemerintahan HB VII, pada masa itu busana tari Srimpi dan Bedhaya berubah menggunakan rompi dan bulu-bulu serta masuknya instrumen trompet dalam unsur iringan, menandai pengaruh Belanda. Dalam segi durasi pertunjukan, sudah dipadatkan, dari yang semula tujuh puluh lima menit menjadi dua puluh lima menit. Menurut Titik Agustin dalam hal properti yang digunakan juga sudah mengalami perubahan. Pada awalnya saat bagian perangan, penari menggunakan jebeng (semacam perisai) dan keris. Kemudian berubah hanya menggunakan keris saja, hingga saat ini (wawancara, 10 Januari 2019).

Masuknya pengaruh barat ini tidak hanya dalam hal keseniannya saja, tetapi juga dalam kehidupan sehari-hari para bangsawan, seperti diungkapkan oleh Purwadmadi (2014, hlm. 30) bahwa “...masa pemerintahan Sri Sultan HB VII adalah masa makin merasuknya pengaruh busana ala Barat dalam kehidupan sehari-hari kalangan bangsawan dan awam".

Mari Condronagoro(dalam Purwadmadi \&Linaras, 2014,hlm.35)mengatakan“Pengaruh itu tidak berhenti pada pengedepanan status sosial saja, tetapi lebih dari itu. Peningkatan kualitas busana tidak saja dilandasi ambisi pribadi guna menunjukan keunggulan, namun mengandung makna yang lebih bagi kepentingan politik". Pada akhirnya, puncak perkembangan tersebut juga dalam hal keterbukaan pihak istana yang kemudian 
mengijinkan tari-tari klasik istana dipelajari oleh masyarakat awam dan dikembangkan di luar tembok keraton termasuk Srimpi dan Bedhaya. Hal ini sebenarnya mengindikasikan bahwa keraton mulai terbuka, tidak lagi borjuis tapi populis. Tampak adanya kesadaran bahwa keberadaan keraton didukung sepenuhnya oleh masyarakat awam.

Untuk cerita Srimpi Pandhelori diambil dari serat Menak Kustub, karya Rg. Yasadipura

I. Cerita tersebut menceritakan peperangan antara Dewi Kadarwati melawan Dewi Ngumyunadikin. Judul tarian diambil dari nama gendhingya yaitu gendhing Pandhelori, ada juga yang menyebut gendhing Bandhilori (hal ini biasa terjadi untuk penyebutan beberapa kata dalam istilah Jawa, antara konsonan P dan B bisa saja bertukar tempat karena keduannya sama-sama konsonan yang dihasilkan oleh bibir /bilabial).

Srimpi Pandhelori merupakan sebuah struktur estetis yang dibangun dari berbagai elemen. Pemahaman terhadap elemen-elemen dalam membangun struktur itu bisa melalui hermeneutic circle (lingkaran hermeneutik), yang mengandung makna bahwa teks harus ditafsirkan secara sirkular: bagianbagian harus dilihat dalam keseluruhan dan sebaliknya keseluruhan harus dipandang juga menurut bagian-bagiannya. Artikel ini difokuskan untuk membahas tata rias dan busana Srimpi Pandhelori agar pembahasan lebih mendalam. Di samping hal tersebut busana dan rias merupakan elemen struktur Pandhelori yang tidak boleh diabaikan karena di dalamnya sejumlah nilai, sejumlah pesan artistik itu dikapsulkan lewat warna, model busana, bentuk dan macam accesories, jenis riasannya dan sebagainya.

Nilai adalah konsep-konsep atau gagasan dari individu, sekelompok individu, atau masyarakat, yang dijadikan pedoman untuk menentukan sikap tentang baik-buruk, benar-salah, pantas-tidak pantas, dan menjadi dasar untuk memberikan penghargaan dan atau mengevaluasi orang lain. Dalam sejumlah hal, nilai tertentu akan bersifat subjektif, artinya tergantung pada individu yang memberikan penilaian, maupun situasi tempat individu itu berada. Setiap individu, sekelompok individu, atau masyarakat memiliki pandangan-pandangannya sendiri mengenai nilai. Konsep-konsep ataupun kesepakatan yang lahir dari suatu masyarakat dipengaruhi oleh norma-norma, aturan, kebiasaan, dan adat istiadat yang berlaku di dalam masyarakat yang bersangkutan. Oleh karena itu pengertian tentang nilai menjadi sangat beragam. Light dkk (1989, hlm. 81) menyatakan bahwa, tak ada nilai-nilai yang bisa diterapkan pada segala situasi. Selalu ada pengecualian. Meskipun demikian nilai-nilai yang dipegang orang cenderung mewarnai cara hidup mereka secara keseluruhan.

Pendidikan pada dasarnya adalah sebuah upaya atau proses untuk mendewasakan dan mengembangkan kemampuan individu secara menyeluruh baik jasmani maupun rohani. Seperti yang tertulis dalam The International Dictionary of Education (Puspositardjo, 2005, hlm. 155) yang memberikan batasan bahwa "Education is the total processes developing human ability and behavior" (pendidikan merupakan proses secara total dari pengembangan 
kemampuan dan tingkah laku manusia). Sementara itu Vygotsky (dalam Moll, 1993, hlm. 1) memandang bahwa, pendidikan tidak sekedar upaya pengembangan kemampuan kognitif saja, tetapi juga merupakan inti dari aktivitas sosiokultural. Pendidikan yang berakar pada kultur bangsa ini juga diungkapkan oleh Ki Hajar Dewantara (2004, hlm. 14-15) bahwa "Pendidikan umumnya berarti daya upaya untuk memajukan bertumbuhnya budipekerti (kekuatan batin, karakter), pikiran (intelek) dan tubuh anak. ...dalam pengertian Taman Siswa tidak boleh dipisah-pisahkan agar kita dapat memajukan kesempurnaan hidup...".

Lebih lanjut Dewantara mengatakan bahwa, pendidikan Nasional menurut paham Taman Siswa adalah pendidikan yang beralaskan garis-garis hidup dari bangsanya (cultural-national), dan diperuntukan untuk keperluan perikehidupan yang dapat mengangkat derajat Negara dan rakyatnya, agar dapat bekerja bersama-sama dengan bangsa lain.

Berdasarkan pengertian nilai dan pendidikan tersebut di atas, dapat dirumuskan bahwa nilai pendidikan merupakan konsep-konsep atau gagasan dari individu, sekelompok individu, atau masyarakat, yang dijadikan pedoman untuk mengembangkan kemampuan individu secara menyeluruh baik jasmani maupun rohani. Konsep-konsep maupun gagasan tersebut bisa berupa karya tari klasik seperti Srimpi Pandhelori, yang di dalam instrumen tata busana dan riasnya berupa simbol-simbol tradisi yang didalamnya mengandung nilai-nilai pendidikan.
Penelitian ini bertujuan mengungkapkan dan menafsirkan nilai-nilai pendidikan dalam tata busanadan rias Srimpi Pandhelori gaya Yogyakarta melalui perspektif hermeneutik serta menganalisis seberapa besar potensi nilai-nilai pendidikan yang terdapat secara simbolis di tata busana dan rias dapat digunakan sebagai media pendidikan. Hasil penelitian diharapkan dapat bermanfaat untuk menambah wawasan dan informasi bagi pemerhati bidang pendidikan bahwa seni tari dapat digali nilai-nilai kependidikannya, sehingga bisa dimanfaatkan sebagai sumber pendidikan nilai untuk memperkokoh pendidikan karakter bagi generasi muda.

\section{METODE}

Penelitian ini adalah penelitian deskriptif kualitatif dengan menggunakan pendekatan hermeneutik, yang bertujuan untuk mengungkapkan nilai-nilai pendidikan dari simbol-simbol tradisi, yaitu nilai pendidikan dalam tata busana dan rias tari Srimpi Pandhelori gaya Yogyakarta. Pendekatan hermeneutik yang digunakan adalah hermeneutik dari Gadamer. Menurut Gadamer tujuan hermeneutik bukanlah menerapkan berbagai macam aturan baku dan kaku untuk meraih pemahaman yang benar objektif, tetapi untuk mendapatkan pemahaman seluas mungkin. Kunci untuk memahami bukan memanipulasi atau menguasai, tetapi dengan partisipasi dan keterbukaan; bukan dengan pengetahuan, tetapi dengan pengalaman; dan bukan dengan metodologi, tetapi dengan dialektika (Palmer, 2016, hlm. 255). Dengan demikian 
dalam penelitian ini peneliti sebagai intepreter melakukan dialog dengan teks, yang dalam hal ini adalah busana dan rias Srimpi Pandhelori untuk mengungkapkan nilai-nilai pendidikan yang terdapat di dalamnya.

Objek material utama penelitian ini adalah gelar/pertunjukan tari Srimpi, oleh karena itu, teknik pengumpulan data yang utama adalah pengamatan secara langsung pertunjukan tari Srimpi, yang diperkuat dengan rekaman. Untuk memperoleh data mengenai Srimpi Pandhelori, peneliti mengamati secara langsung gelar pertunjukan tari Srimpi Pandhelori di Bangsal Sri Manganti Kraton Yogyakarta, sekaligus merekam pertunjukan tersebut. Dalam kegiatan pengamatan secara langsung ini sekaligus peneliti memilahmilah satuan datanya, sehingga diperoleh data mengenai elemen-elemen yang mendukung pertunjukan Srimpi Pandhelori, salah satunya adalah tata busana dan riasnya. Untuk memperoleh keabsahan data, peneliti melakukan pengamatan yang berulang-ulang melalui rekaman pertunjukan Srimpi Pandhelori (hal ini sekaligus untuk mendapatkan data yang lebih detail mengenai tata busana dan rias Srimpi Pandhelori), trianggulasi metode dan sumber dengan mewawancarai tiga orang informan, melakukan diskusi dengan teman sejawat, dan juga membaca beberapa referensi yang mendukung.

Analisis data dilakukan dengan menggunakan pendekatan hermeneutika dialektis, di mana prosedur penafsiran dalam rangka memperoleh makna menggunakan unsur-unsur analisis dari Madisson (1990, hlm. 29-30) yang disebutnya sebagai metode normatif. Metode Madisson ini peneliti gunakan untuk mengarahkan tindakan peneliti sebagai intepreter, dalam mengintepretasikan nilai-nilai pendidikan yang secara simbolis terdapat dalam tata busana dan rias Srimpi Pandhelori. Terdapat sepuluh metode intepretasi dari Madisson, namun dalam penelitian ini hanya digunakan empat metode saja yaitu:

1. Koherensi, tafsir terhadap karya seorang pengarang harus menjadi koheren dalam karya itu sendiri, yaitu menyajikan gambaran yang tersatukan dan tidak terjadi kontradiksi dalam karya tersebut. Dalam ungkapan Gadamer (1975, hlm. 259), harmoni antara semua rincian dengan keseluruhan merupakan kriteria pemahaman yang benar. Kegagalan mencapai harmoni berarti pemahaman telah gagal. Berangkat dari pemaknaan tata rias dan busana srimpi Pandhelori inilah koherensi dengan elemen lain dibangun pada kajian selanjutnya.

2. Kekomprehensifan, prinsip kekomprehensifan memperhatikan hubungan tafsir dengan karya yang ditafsirkan. Artinya dalam menafsirkan pikiran-pikiran pengarang (kreator) penafsir harus memperhitungkan pikiranpikiran itu sebagai sebuah keseluruhan dan tidak menolak karya-karya yang relevan dengan itu.

3. Kontekstualitas, karya seorang pengarang tidak boleh dibaca lepas konteks, yakni kaitan karya itu dengan konteks kultural dan historisnya. Oleh karena itu, dalam mengungkapkan nilai-nilai pendidikan 
tata busana dan rias Srimpi Pandhelori, peneliti sebagai intepreter juga melihat kaitan karya tari ini dengan situasi kultural dan historisnya pada masa pemerintahan HB VII.

4. Penetrasi, intepreter memasukan dirinya pada wilayah kreator, untuk memahami intensi (maksud, kehendak) sang kreator. Intepretasi yang baik seharusnya menembus ke dalam. Intepreter masuk menerobos kulit gejala sehingga sampai pada hakekat kenyataan. Dalam hal ini peneliti berusaha memasuki wilayah kreator tari Srimpi Pandhelori, agar dapat memahami maksud kreator lebih dalam lagi.

\section{HASIL DAN PEMBAHASAN}

\section{Tata Busana dan Rias Srimpi Pandhelori}

Busana di dalam tari bisa dikategorikan menjadi tiga bagian, busana bagian kepala, busana pada bagian torso dan busana pada bagian kaki. Busana kepala meliputi accesories yang dikenakan di kepala. Busana badan meliputi pakaian dan accesories yang dikenakan di bagian badan. Sedangkan busana kaki adalah segala sesuatu yang dikenakan di kaki penari. Untuk desain/tata busana pada tari klasik gaya Yogyakarta putri pada umumnya terdiri dari busana kepala dan torso. Adapun tata busana pada tari Srimpi Pandhelori adalah sebagai berikut:

\section{a. Busana pada Kepala}

Busana pada bagian kepala merupakan accesories yang menggambarkan identitas penari sebagai puteri keraton. Lebih menggambarkan keagungan, keanggunan putri dari dalam istana. Untuk itu, pada bagian kepala penari dipasangkan accessories sebagai berikut: Sinyong merupakan visualisasi dari sanggul, terbuat dari kain yang di dalamnya diisi kapas sehingga ringan dan mudah ditusuk, berwarna hitam. Pelik, terbuat dari kertas berwarna putih yang dipotong menyerupai bentuk bunga Melati, ditempelkan pada sanggul bagian belakang.

Jebehan ceplok pada awalnya merupakan tiruan bunga mawar yang dibuat dari kain sutera. Dipasang di kanan-kiri pada sinyong (jebehan: untaian tiga bunga mawar), dan ceplok dipasang di bagian belakang sanggul tepat di tengahnya. Mentul, hiasan sanggul yang bentuknya mirip dengan setangkai bunga. Jumlahnya ada lima buah, merupakan simbol lima nafsu manusia yaitu kasih sayang, kenikmatan, keinginan, kekuasaan, dan kesucian. Jungkat sering disebut pethat yang berbentuk gunungan merupakan lambang keagungan Tuhan dan terciptanya kebahagiaan (Condronagoro, 2010, hlm. 121).

Jamang adalah mahkota yang terbuat dari kulit yang dipulas dengan warna emas dan dipasangkan permata. Bulubulu, mendapat pengaruh dari gaya sanggul wanita Inggris pada abad XVIII, yang meletakan bulu-burung Unta atau Kasuari di bagian depan sanggulnya (Suprianto, 2013, hlm. 4 ). Sumping, yang dikenakan adalah sumping jenis ron (daun) biasa disebut ronsumping, sumping 


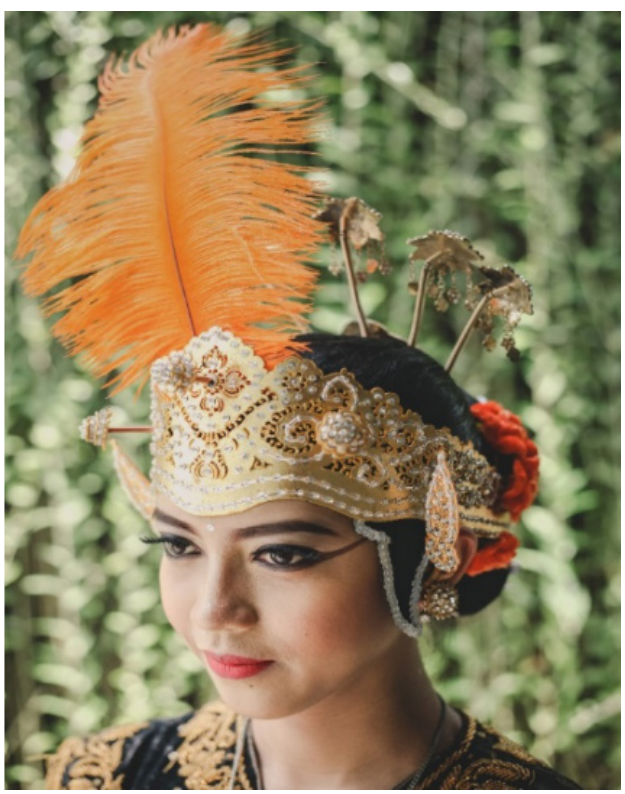

Gambar 1. Busana kepala

(Sumber foto: Wenti Nuryani, 2018)

yang bentuknya menyerupai daun.

Menurut peneliti kata sumping merupakan pemendekan dari sumpel kuping (menutup telinga dengan sesuatu). Sengkang (sengkang ronyok), yaitu hiasan yang dikenakan pada telinga kanan dan kiri dan terbuat dari emas berlian.

\section{b. Busana pada bagian Torso}

Busana pada bagian torso merupakan busana yang dipakai untuk menggambarkan puteri keraton, yang ditandai dengan ragam hias yang melekat ala busana yang dikenakan. Untuk itu, penari Srimpi Pandhelori mengenakan rincian busana sebagai berikut; rompi, sampur, slepe, kelat bahu, kalung susun, gelang kana, dan mengenakan property sebuah keris. Rompi, baju dari kain beludru dengan bordiran benang atau payet warna emas, tanpa lengan. Mulai dikenakan oleh penari srimpi di masa HB ke VIII (Kawendrosusanta, 1981, hlm.
164) . Pemakaian baju rompi ini dikatakan sudah ada pengaruh dari Eropa, seperti halnya hiasan bulu-bulu di kepala yang diselipkan pada jamang (Supriyanto, 2009, hlm. 4).

Sampur, atau sonder menggunakan sampur dengan motif cindhe berwarna merah. Slepe, sabuk bagian luar (ikat pinggang) yang dikenakan setelah sampur, lengkap dengan bathokan-nya. Kelat Bahu yang dipakai adalah kelat bahu yang disebut Nagamamangsa (naga memangsa sesuatu). Bentuknya seekor naga yang menurut pengertian orang Jawa adalah lambang kemakmuran. Kalung susun, bentuknya tanggalan (bulan muda), jumlahnya gasal (bersusun tiga). Gelang, yang dipakai adalah sepasang gelang kana. Kana artinya simpai atau suh. Memakai gelang kana artinya agar menyadari fungsi dirinya sebagai suh (pengikat). Keris, yang dipakai adalah keris wanita, sehingga bentuknya kecil. Menggunakan oncen keris yang terbuat dari benang yang berwarnawarni. Keris ini berfungsi sebagai property tari, digunakan saat bagian perangan.

Penari Srimpi Pandhelori juga mengenakan kain batik dengan motif yang biasa digunakan para putra-putri dalem. Biasanya mengenakan kain batik motif lereng, parang. Motif ini menjadi bagian penting sebagai simbol status sosial dalam lingkungan istana. Untuk itu, penari Srimpi Pandhelori mengenakan kain batik parang gurdha. 


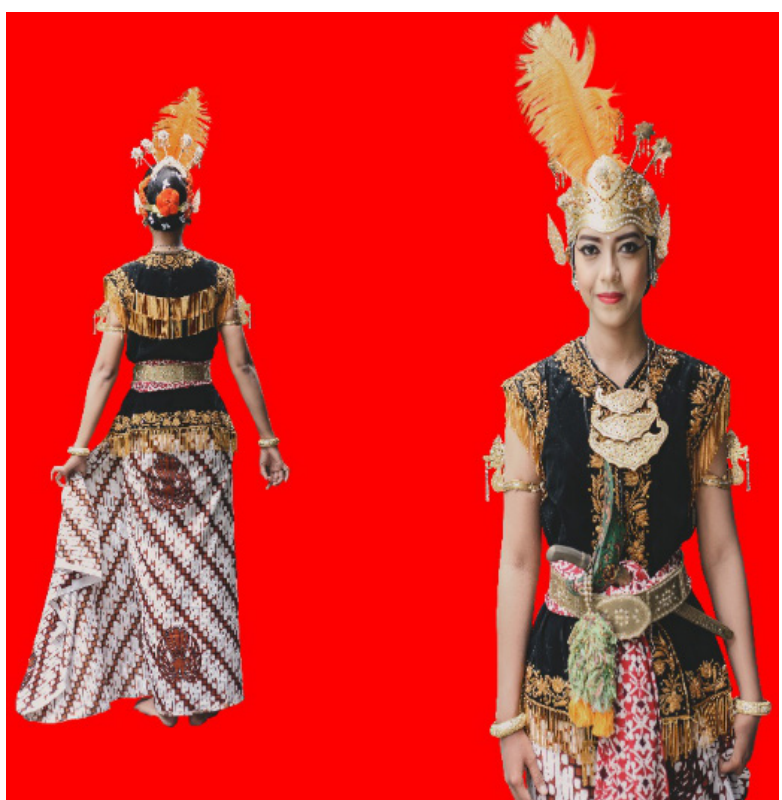

Gambar 2. Busana badan dan kepala tampak depanbelakang

(Sumber foto: Wenti Nuryani, 2018)

2. Nilai-nilai Pendidikan tata busana dan Rias Srimpi Pandhelori

\section{a.Simbol dan Arti dalam Busana}

Busana dan accesories yang dikenakan dalam tari Srimpi Pandhelori tersebut tidak sekedar untuk memenuhi unsur estetisnya saja, namun dibalik itu ada artinya, atau mengandung maksud tertentu yang diselaraskan dengan maksud tariannya. Berkaitan dengan hal ini Maryono (2015), hlm. 222) mengungkapkan bahwa "jenisjenis simbolis bentuk dan warna busana para penari mempunyai peranan sebagai identitas peran, karakteristik peran, dan ekspresi estetis. bentuk atau mode busana dalam pertunjukan tari tersebut dapat mengarahkan penonton pada pemahaman jenis peran atau figur tokoh".

Ungkapan Maryono ini menunjukan bahwa tata rias dan busana pada pertunjukan tari tidak sekedar untuk memenuhi unsur keindahan saja, namun dibalik itu ada maksud tertentu (intensi) yang hendak disampaikan oleh koreografer kepada penonton. Meskipun hal ini tidak serta merta membuat penonton memahami arti dan nilainilai yang secara simbolis terdapat pada tata rias dan busana tersebut, namun paling tidak mampu membawa imajinasi penonton masuk lebih dalam lagi untuk memahami karakter tokoh, peran, ataupun maksud tarian. Tidak semua bagian busana yang dikenakan dalam tari Srimpi Pandhelori mengandung maksud tertentu, beberapa accessories yang dikenakan murni untuk memenuhi unsur keindahan saja.

Mentul, yaitu hiasan sanggul yang bentuknya mirip dengan setangkai bunga. Jumlahnya ada lima buah, merupakan simbol lima nafsu manusia yaitu kasih sayang, kenikmatan, keinginan, kekuasaan, dan kesucian. Bentuk ini mengandung arti bahwa (pengantin) wanita diharapkan dapat menguasai kelima nafsu tersebut agar dapat menjadi wanita yang utama (Widayanti 2011, hlm. 247). Berkaitan dengan hal ini Dwikurniarini (2014, hlm. 84) mengungkapkan bahwa, pada dasarnya cundhuk mentul bentuknya adalah ceplik (seperti halnya sengkang). Ceplik ini menggambarkan matahari dan sinarnya. Matahari adalah lambang pemberi kehidupan, yang memberikan kehangatan (manfaat) bagi semua makhluk hidup tanpa pandang bulu (tidak membedabedakan).

Dengan demikian cundhuk mentul merupakan lambang hidup. Matahari mempunyai arti positif, memberi manfaat bagi semua makhluk hidup, tanpa pandang bulu. Jumlah mentul yang dipakai adalah 
lima buah. Demikian pula halnya dengan sengkangnya yang supaya kelihatan lebih baik dan hebat temunggul-nya, satu yang di tengah masih ditambah pengarak (pinggiran) hingga dinamakan sengkang ronyok. Dari pendapat ketiganya ini bisa digaris bawahi bahwa cundhuk mentul yang berjumlah lima yang dipakai penari Srimpi memiliki arti, dalam kehidupan manusia harus mampu mengendalikan kelima nafsu yang senantiasa mengiringi langkah manusia dalam mencapai tujuan hidup. Sehingga hidup kita bermanfaat tidak hanya bagi kita sendiri tetapi juga bagi orang lain, lingkungan sosial dan alam.

Jungkat, atau sering disebut pethat yang berbentuk gunungan merupakan lambang keagungan Tuhan dan terciptanya kebahagiaan (Condronagoro, 2010, hlm. 121). Di dalam wayang kulit, bentuk gunungan yang meruncing ke atas ini mempunyai makna sangkan paraning dumadi (asal muasal kehidupan). Hal ini mengingatkan kepada kita semua tentang arah dan tujuan hidup, bahwa pada akhirnya hidup kita akan kembali kepada Sang Khalik. Di samping hal tersebut, gunungan juga melambangkan semua kehidupan yang terdapat di dalam jagad raya.

Jamang, adalah mahkota yang terbuat dari kulit dipulas dengan warna emas dihiasi permata, menjadi simbol status sosial sebagai putri raja. Accessories ini merepresentasikan kemuliaan dan kewibawaan sebagai puteri raja. Bulu-bulu, mendapat pengaruh dari gaya sanggul wanita Inggris pada abad XVIII, yang meletakan bulu-burung Unta atau Kasuari di bagian depan sanggulnya (Suprianto, 2013, hlm. 4 ). Kokar bulu mereprentasikan integritas sosial raja dan keluarganya di tengah-tengah pergaulan istana. Tradisi kirim tanda mata, tali asih antar raja-raja, termasuk bulu-bulu, benda yang lain itu menjadi simbol integritas raja dan kerajaannya maka disisipkan sebagai accesories untuk menghormati hubungan antar dua kerajaan.

Sumping, yang dikenakan adalah sumping jenis ron (daun) biasa disebut ronsumping, sumping yang bentuknya menyerupai daun. Menurut peneliti kata sumping merupakan pemendekan dari sumpel kuping (menutup telinga dengan sesuatu). Artinya, kita harus bisa menyaring berita atau informasi yang kita dengar, tidak semua dimasukan ke dalam hati mentah-mentah. Harus disaring mana informasi yang benar, mana yang sekedar issue (sekarang: hoax). Sumping terbuat dari kulitan dipasang di telinga, bagian bawah dihiasi dengan untaian benang warna-warni dan kertep, berwarna emas yang bermakna keagungan. Sengkang (sengkang ronyok), yaitu hiasan yang dikenakan pada telinga kanan dan kiri dan terbuat dari emas berlian. Wujud sengkang yang bercahaya mengandung makna meningkatnya pengetahuan manusia melalui cahaya kehidupan dan harapan terciptanya sesuatu yang abadi.

Kain (jawa: jarik) parang gurdha, motif parang polanya berbentuk pedang yang sering dipakai para kesatria. Sedangkan motif gurdha, berasal dari kata garuda, yaitu nama sejenis burung besar yang menurut pandangan hidup orang Jawa khususnya Yogyakarta mempunyai kedudukan yang sangat penting. Bentuk motif gurda ini terdiri dari dua buah sayap (lar) dan ditengah-tengahnya terdapat 
badan dan ekor. Burung ini dianggap sebagai burung yang teguh timbul tanpa maguru, yang artinya sakti tanpa berguru kepada siapapun.

Versi lain mengenai motif parang ini (dalam situs resmi Keraton Yogyakarta ) dijelaskan bahwa, motif parang diciptakan Panembahan Senapati saat mengamati gerak ombak Laut Selatan yang menerpa karang di tepi pantai. Sehingga pola garis lengkungnya diartikan sebagai ombak lautan yang menjadi pusat tenaga alam. Dalam hal itu yang dimaksud adalah kedudukan raja. Komposisi miring pada motif parang ini juga menjadi lambang kekuasaan, kebesaran, kewibawaan, dan kecepatan gerak. Memakai kain motif parang gurdha diyakini akan menambah kekuatan dan kesaktian pemakainya. Oleh karena itu, di keraton Yogyakarta tidak sembarang orang diperkenankan memakai kain motif ini. Bahkan sejak jaman HB I (1785) batik parang rusak telah menjadi batik larangan.

Pemakaian kain tradisional motif tertentu yang berkaitan dengan ritual tertentu juga diungkapkan oleh Ciptandi (2016, hlm. 262), bahwa "latar belakang pembuatan kain tradisional adalah untuk kebutuhan acaraacara yang bersifat ritual bagi beberapa kelompok masyarakat tertentu". Ungkapan Ciptandi ini bisa diperkaya dengan melihat beberapa acara ritual seperti upacara adat perkawinan di daerah Yogyakarta (tidak tertutup kemungkinan di daerah lain) kain batik yang dikenakan oleh kedua mempelai biasanya menunjuk pada motif tertentu seperti: wahyu tumurun, sidoluhur, sidomukti. Semuanya itu memiliki nilai filosofis, yang berkaitan dengan doa dan harapan-harapan yang mulia bagi mempelai.

Slepe, sabuk bagian luar (ikat pinggang) yang dikenakan setelah sampur, lengkap dengan bathokannya. Terbuat dari kulitan, mengandung makna sebagai peringatan untuk mengendalikan nafsu birahi, karena apabila terlepas maka kesucian wanita akan hilang. Makna simboliknya, selain harus selalu dekat dengan Sang Pencipta, manusia juga harus memiliki iman yang kuat.

Kelat Bahu, yang dipakai adalah kelat bahu yang disebut Nagamamangsa (naga memangsa sesuatu). Bentuknya seekor naga yang menurut pengertian orang Jawa adalah lambang kemakmuran. Misalnya bagi petani Jawa kalau ada ular (ular sawah) yang masuk ke dalam rumah dianggap sebagai pertanda bahwa sawahnya akan menghasilkan padi yang banyak dan rejekinya juga akan menjadi banyak (Kawendrasusanta, 1981, hlm. 166). Sementara itu Widayanti (2011, hlm. 249) mengatakan bahwa "kelatbahu naga ini merupakan simbol bersatunya pola rasa dengan pola pikir. Arti yang terkandung di dalamnya ialah suatu harapan untuk mendapatkan rejeki dan kekuatan dalam menjalani hidup".

Kalung susun, bentuknya tanggalan (bulan muda), jumlahnya gasal (bersusun tiga). Melambangkan kewanitaan, jumlah gasal menunjukan sifat positif. Secara keseluruhan memberi arti hidup (Kawendrasusanta, 1981, hlm. 166). Berkaitan dengan arti dari Kalung Susun ini, Condronagoro (2010, hlm. 120) maupun Widayanti (2011, hlm. 149) keduanya mengungkapkan bahwa, mengungkapkan bahwa "tiga tingkatan dalam kalung susun 
merupakan lambang dari tiga tingkatan kehidupan manusia yaitu: lahir, kawin, mati (alam fana, alam antara, dan alam baka)".

Gelang, yang dipakai adalah sepasang gelang kana. Kana artinya simpai atau suh. Memakai gelang kana artinya agar menyadari fungsi dirinya sebagai suh (pengikat). Keris yang dipakai adalah keris wanita, sehingga bentuknya kecil. Menggunakan oncen keris yang terbuat dari benang yang berwarnawarni. Keris ini berfungsi sebagai properti tari, digunakan saat bagian perangan.

\section{b. Rias Wajah}

Rias Wajah tari Srimpi Pandhelori merupakan rias yang menggambarkan putri keraton yang cantik. Jenis riasnya menggunakan teknik rias jahitan seperti pada riasan mata penganten Paes Ageng gaya Yogyakarta. Jahitan pada mata dibentuk menggunakan pensil alis warna coklat. Maknanya untuk memperjelas penglihatan supaya lebih fokus, dapat membedakan baik dan buruk, yang kemudian dinalar sehingga dapat dijadikan pegangan yang kuat selama hidup. Makna tersebut tergambar pada jahitan mata yang berupa dua garis menuju ke pelipis (Widayanti, 2011, hlm. 247).

Pada awalnya, bedak yang digunakan adalah boreh atau lulur yang berwarna kuning, ditambah dengan pemakaian pemerah bibir (lipstik) dan gincu (sekarang rouge: pemerah pipi). Dibalurkan pada wajah, tangan, dan kaki serta berbau harum. Dalam perkembangannya hingga saat ini boreh atau lulur hanya dikenakan di lengan tangan dan kaki saja. Sementara untuk wajahnya sudah

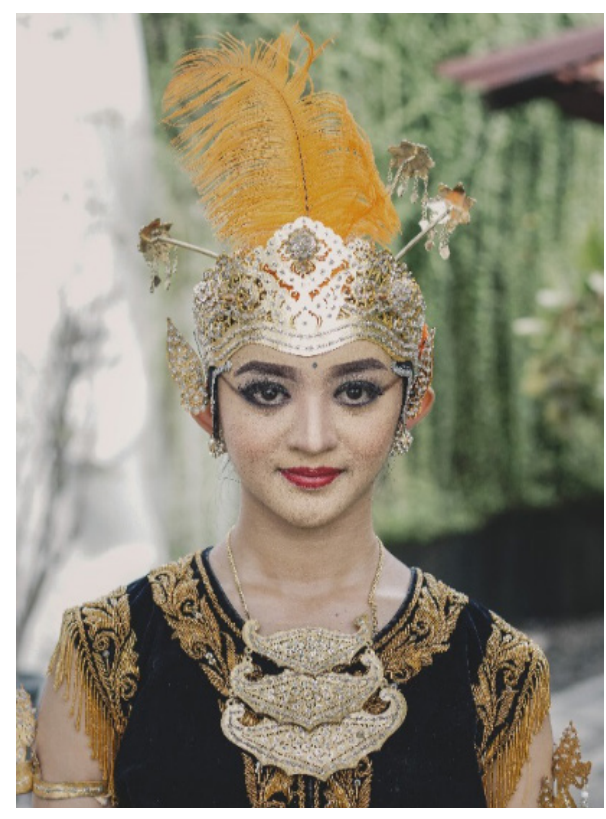

Gambar 3. rias mata jahitan (Foto, Wenti Nuryani, 2018)

menggunakan bahan riasan yang modern yaitu menggunakan alas bedak (fondation), dilanjutkan dengan bedak tabur dan bedak padat, yang merknya sangat beragam.

\section{Nilai-Nilai Pendidikan Busana dan Rias}

\section{Tari Srimpi Pandhelori}

Setelah simbol-simbol tradisi yang terdapat di dalam busana dan rias Srimpi Pandhelori diungkapkan, tampak adanya nilainilai pendidikan yang dapat dimanfaatkan sebagai media pendidikan untuk menunjang pendidikan karakter. Dalam penataan rias busana tari tersebut didasarkan pada narasi simbolik filsafat hidup dalam budaya Jawa.

a. Nilai pendidikan yang berkaitan dengan pengendalian diri (mengendalikan nafsu birahi) agar hidup manusia memiliki arti baik untuk diri sendiri, orang lain, lingkungan sosial dan alam. Senantiasa mendekatkan diri pada Sang Khalik dan teguh imannya. Hal ini dapat diamati pada makna simbolis slepe, sabuk bagian 
luar (ikat pinggang) yang dikenakan setelah sampur, lengkap dengan bathokannya. Terbuat dari kulitan, mengandung arti sebagai peringatan untuk mengendalikan nafsu birahi, karena apabila terlepas maka kesucian wanita akan hilang. Nilai pengendalian diri juga dapat dicermati pada arti simbolis cundhuk mentul yang berjumlah lima yang dipakai penari Srimpi memiliki arti dalam kehidupan manusia harus mampu mengendalikan kelima nafsu yang senantiasa mengiringi langkah manusia dalam mencapai tujuan hidup. Sehingga hidup kita bermanfaat tidak hanya bagi kita sendiri tetapi juga bagi orang lain, lingkungan sosial dan alam.

b. Nilai pendidikan yang berkaitan dengan sangkan paraning dumadi (asal muasal hidup). Adanya kesadaran tentang tujuan akhir hidup manusia ini akan menuntun manusia ke arah kebaikan. Hal ini dapat diamati pada makna simbolis Jungkat, atau sering disebut pethat yang berbentuk gunungan merupakan lambang keagungan Tuhan dan terciptanya kebahagiaan (Condronagoro, 2010, hlm. 121). Di dalam wayang kulit, bentuk gunungan yang meruncing ke atas ini mempunyai makna sangkan paraning dumadi (asal muasal kehidupan). Hal ini mengingatkan kepada kita semua tentang arah dan tujuan hidup, bahwa pada akhirnya hidup kita akan kembali kepada Sang Khalik

c. Nilai pendidikan yang berkaitan dengan kejelian, kecermatan dalam menyaring informasi yang kita terima.
Sejalan dengan tingkat kemajuan dalam bidang IT, komunikasi antar wilayah, negara, benua bisa terjalin dengan begitu mudahnya, dan seakan tanpa batas. Efek samping dari hal ini adalah masuknya informasi-informasi yang belum tentu benar, seperti saat ini banyak berita-berita hoax memenuhi media sosial. Hal ini apabila tidak dicermati akan menimbulkan berbagai konflik. Nilai ini dapat diamati pada makna simbolis sumping. Kata sumping merupakan pemendekan dari sumpel kuping (menutup telinga dengan sesuatu). Artinya, kita harus bisa menyaring berita atau informasi yang kita dengar, tidak semua dimasukan ke dalam hati mentah-mentah. Harus disaring mana informasi yang benar, mana yang sekedar issue (sekarang: hoax).

d. Nilai pendidikan yang berkaitan dengan membangun kegigihan dalam menghadapi tantangan hidup, berani mandiri dan cekatan. Nilai ini terlihat pada jarik (kain) penari yang bermotif parang gurdha, berasal dari kata garuda, yaitu nama sejenis burung besar yang menurut pandangan hidup orang Jawa khususnya Yogyakarta mempunyai kedudukan yang sangat penting. Bentuk motif gurda ini terdiri dari dua buah sayap (lar) dan ditengah-tengahnya terdapat badan dan ekor. Burung ini dianggap sebagai burung yang teguh timbul tanpa maguru, yang artinya sakti tanpa berguru kepada siapapun.

e. Nilai pendidikan yang berkaitan dengan menyelaraskan cipta, rasa, 
dan karsa, harapannya agar diperoleh kemudahan dalam mencapai cita-cita, rejeki, dan kuat (tabah) dalam menjalani kehidupan. Hal ini disimbolkan dalam kelatbahu naga, yang merupakan simbol bersatunya pola rasa dengan pola pikir. Arti yang terkandung di dalamnya ialah suatu harapan untuk mendapatkan rejeki dan kekuatan dalam menjalani hidup.

f. Nilai pendidikan yang berkaitan dengan pemahaman tentang tiga tahapan kehidupan manusia yaitu, lahir, hidup, dan mati. Kesadaran akan tahapan kehidupan manusia ini akan mengarahkan perilaku dan sikap manusia dalam mencapai tujuan hidup. Bahwa manusia tidak boleh hanya mementingkan kehidupan di dunia, namun juga harus mempersiapkan bekal di alam baka. Secara simbolis terdapat pada kalung susun, hal ini telah dijelaskan bahwa tiga tingkatan dalam kalung susun merupakan lambang dari tiga tingkatan kehidupan manusia yaitu lahir, kawin, dan mati (alam fana, alam antara, dan alam baka).

Nilai-nilai pendidikan tersebut, sejauh pengamatan peneliti, masih relevan apabila dimanfaatkan sebagai media pendidikan di era millenia ini karena pendidikan mengenai ketuhanan, pengendalian diri, kegigihan, kemandirian, kecermatan, dan keselarasan cipta-rasa-karsa, merupakan nilai-nilai yang bersifat universal dan penting ditanamkan kepada setiap orang, terutama generasi muda sebagai generasi penerus.

Memanfaatkan seni tradisional seperti tari Srimpi, wayang kulit, dan seni-seni tradisional lainnya sebagai media pendidikan ini penting dilakukan karena mengandung nilai-nilai filososfis yang tinggi, berkaitan dengan nilai moral, budi pekerti, dan nilai-nilai kehidupan yang lain. Sekaligus merupakan upaya untuk memperkokoh jati diri bangsa. Kokohnya jati diri suatu bangsa ini berpengaruh terhadap ketahanan Nasional bangsa yang bersangkutan. Dalam hal ini Sayuti mengungkapkan bahwa,

... sebagai bangsa yang memiliki kosa-budaya yang melimpah ruah, apapun bentuk dan wujudnya, budaya bangsa tersebut merupakan dan menjadi modal dan identitas, benteng, serta sekaligus sebagai paspor utama, terlebih lagi, dalam tata pergaulan dan tegur-sapa global. Budaya merupakan modal dan identitas kita dalam berelasi dan berinteraksi dengan yang lain, yang bukan kita, liyan, the others. ... Sementara itu, proses berelasi dan berinteraksi dengan yang lain itu juga meniscayakan masuknya beragam nilai secara tak terhindarkan, yang dalam sejumlah hal acapkali bertentangan dengan nilai-nilai yang sudah lama terinternalisasi dan diyakini. Dalam konteks inilah, nilainilai yang inheren dalam kosa-budaya bangsa berfungsi sebagai benteng (2016, hlm. 1)

Apa yang diungkapkan oleh Sayuti ini menunjukan betapa pentingnya melestarikan berbagai macam bentuk seni sebagai salah satu kekayaan budaya Nusantara yang merupakan identitas dan jati diri bangsa Indonesia, sekaligus sebagai filter dan benteng dari pengaruh budaya luar yang 
kurang sesuai dengan konteks keindonesiaan. Tentu saja harus disertai dengan revitalisasi, rekontekstualisasi, rekonstruksi (bila perlu) menyesuaikan dengan perkembangan jaman dan kemajuan di bidang teknologi.

Dewantara (2013, hlm

menjelaskan tujuh manfaat mempelajari tari srimpi yaitu, (1) Tari srimpi itu memiliki sifat pendidikan gerak badan dan rasa keindahan (pendidikan jasmani dan aesthetika), (2) Tari srimpi itu bersifat sport, yang menghaluskan dan menyehatkan tubuh (3) Tari srimpi itu mendidik wirama, yakni mengekang diri, dan gerak wiraga, yakni kesusilaan (4) Tari srimpi itu menarik gadis kepada rasa kesenian (5) Tari srimpi itu menarik gadis kepada rasa kesucian (6) Tari srimpi itu suatu alat atau senjata untuk menolak sifat-sifat adat-istiadatyang kasar dari gadis-gadis kita, yang jadi korban pendidikan cara barat. Yaitu yang umumnya tidak dapat membedakan mana adat-istiadat yang baik, mana yang jelek dan jahat (7) Tari srimpi itu pusaka indah dari leluhur kita, yang terbilang suatu cahaya keadaban; oleh karenanya harus kita hidupkan, kita muliakan, dan kita sebarkan. Kita pelihara serta kita populerkan sehingga tidak akan mati, atau hidup tetapi di negeri lain

Dari ungkapan Dewantara ini dapat digaris bawahi bahwa, mempelajari tari Srimpi dapat menghaluskan budi pekerti dan menyehatkan badan karena mengandung unsur-unsur sport. Di samping hal tersebut, dengan mempelajari tari Srimpi seseorang dapat belajar mengenai keindahan (estetika), karena di dalam desain tata busana dan tata riasnya sarat dengan nilai-nilai keindahan.
Bagi seorang wanita memahami tentang unsur-unsur keindahan ini penting, karena hal ini berkaitan dengan kemampuan untuk ngadi sarira dan ngadi busana. Ngadi sarira dan busana secara filosofis memiliki arti sebagai upaya untuk merawat diri baik lahir maupun batin, secara total dan menyeluruh melalui perawatan diri/mempercantik diri dan memperindah busana, serta menguasai tata krama di dalam pergaulan. Dengan demikian keanggunan seorang wanita akan dilihat tidak sekedar dari sisi wajahnya yang cantik saja, atau busananya yang indah saja, tetapi juga kesantunannya dalam pergaulan sehari-hari.

\section{PENUTUP}

Tari Srimpi pada awalnya merupakan media untuk pendidikan putri-putri raja dan bangsawan lainnya, terutama untuk mendidik etika dan budi pekerti wanita di kalangan istana. Oleh karena itu, tarian ini sarat dengan nilai-nilai pendidikan yang berkaitan dengan etika, sopan-santun, dan tata krama, yang lahir dari kearifan lokal budaya Jawa. Meskipun lahir dari kearifan lokal budaya Jawa, namun esensi nilai-nilainya bisa diterapkan untuk umum, tidak terbatas kalangan masyarakat Jawa saja. Demikian pula nilai-nilai pendidikan yang terdapat di dalam tata rias dan busana Srimpi Pandhelori, nilai-nilai tersebut bersifat universal, meskipun lahir dari konsep budaya Jawa. Di samping hal tersebut, nilainilai pendidikan dalam tata rias dan busana srimpi Pandhelori, masih relevan dimanfaatkan sebagai media pendidikan, terutama dalam hal pendidikan nilai, moral, dan budi pekerti. 
Secara simbolis slepe, sabuk bagian luar (ikat pinggang) yang dikenakan setelah sampur, lengkap dengan bathokan-nya, terbuat dari kulitan, mengandung arti sebagai peringatan untuk mengendalikan nafsu birahi, karena apabila terlepas maka kesucian wanita akan hilang. Arti simbolis cundhuk mentul yang berjumlah lima yang dipakai penari Srimpi merupakan simbol bahwa dalam kehidupan manusia harus mampu mengendalikan kelima nafsu yang senantiasa mengiringi langkah manusia dalam mencapai tujuan hidup. Sehingga hidup kita bermanfaat tidak hanya bagi kita sendiri tetapi juga bagi orang lain, lingkungan sosial dan alam.

Secara simbolis Jungkat, atau sering disebut pethat yang berbentuk gunungan merupakan lambang keagungan Tuhan dan terciptanya kebahagiaan (Condronagoro, 2010, hlm. 121). Di dalam wayang kulit, bentuk gunungan yang meruncing ke atas ini mempunyai makna sangkan paraning dumadi (asal muasal kehidupan). Hal ini mengingatkan kepada kita semua tentang arah dan tujuan hidup, bahwa pada akhirnya hidup kita akan kembali kepada Sang Khalik.

Sumping merupakan pemendekan dari sumpel kuping (menutup telinga dengan sesuatu). Memiliki arti harus bisa menyaring berita atau informasi yang diperoleh, tidak semua dimasukan ke dalam hati mentahmentah. Bentuk motif kain gurda ini terdiri dari dua buah sayap (lar) dan ditengahtengahnya terdapat badan dan ekor. Burung dipersepsikan sebagai burung yang teguh timbul tanpa maguru, yang artinya sakti tanpa berguru kepada siapapun.
Kelatbahu naga, merupakan simbol bersatunya pola rasa dengan pola pikir. Arti yang terkandung di dalamnya ialah suatu harapan untuk mendapatkan rejeki dan kekuatan dalam menjalani hidup. Kalung susun hal ini telah dijelaskan bahwa tiga tingkatan dalam kalung susun merupakan lambang dari tiga tingkatan kehidupan manusia yaitu lahir, kawin, dan mati (alam fana, alam antara, dan alam baka).

Mengingat kandungan nilai-nilai pendidikan yang penting dalam Srimpi Pandhelori, maka mengajarkan tarian ini kepada generasi muda menjadi suatu hal yang merupakan keniscayaan. Meskipun untuk mewujudkan hal ini perlu upaya yang terus menerus karena gerusan arus globalisasi semakin tak terbendung, sehingga masuknya berbagai macam jenis seni yang lebih mencitrakan kekinian menjadi begitu mudah dan menggoda kalangan generasi muda millenia.

\section{Daftar Pustaka}

Cahya. 2016. Nilai, Makna, dan Simbol Dalam Pertunjukan Wayang Golek Sebagai Representasi Media Pendidikan Budi Pekerti. Panggung 26 (2), 117-127.

Ciptandi, Fajar, Sachori. A\& Haldani. A. 2016. Fungsi dan Nilai pada Kain Batik Tulis Gedhog khas Masyarakat di Kecamatan Kerek, Kabupaten Tuban, Jawa Timur. Panggung, 26 (3), 261-271. 
Condronagoro, Mari. 2010. Memahami Busana Adat Kraton Yogyakarta, Warisan Penuh Makna. Yogyakarta: Yayasan Pustaka Nusutama.

Dewantara, KH. 2004. Pendidikan Bagian I. Yogyakarta: Majelis Luhur Persatuan Taman Siswa.

Dwikurniarini, Dina. 2014. Simbolisme Seni Dalam Budaya Jawa Di Era Global: Suatu Kajian Dari Batik Dan Tari Klasik Gaya Yogyakarta. MOZAIK, Jurnal Ilmu-Ilmu Sosial dan Humaniora 6 (1), 78-90.

Faiz, Fakhruddin. 2002. Hermeneutika alQur'an. Yogyakarta: Qolam, Cet.III.

Gadamer, Hans, Georg. 1975. Thruth and Method: Diterjemahkan oleh Ahmad Sahidah. 2010. Kebenaran dan Metode. Yogyakarta: Pustaka Pelajar.

Gasiyah. 2015. Media Pembelajaran Interatif Seni Tari Srimpi Menggunakan Adobe Flash CS5. Proseding Seminar Nasional Universitas PGRI Yogyakarta, 396-401.

Kawendrasusanta, Kuswaji. 1981. B B s a n a Tari Klasik Gaya Yogyakarta,

Yogyakarta" Fred Wibowo.(Ed),Mengenal Tari

Klasik Gaya Yogyakarta, Yogyakarta: Bidang Kesenian Propinsi DIY.

Lindsay, Jennifer. 1991. Klasik, Kitsch, Kontemporer: Sebuah Studi tentang Seni Pertunjukkan Jawa. Yogyakarta: Gadjah Mada University Press

Madison, G.B. 1990. The Hermeneutics of Post Modernity. Indiana University Press.

Maryono. 2015. Makna Pragmatik Tindak Tutur Direktif Pada Tari Gathutkaca

Gandrung. Panggung 25 (3), 211-226.

Moll, C. Luis. 1990. Vygotsky and Education. Instructional Implications and Applications of Sociohistorical Psychology. Cambrigde University Press.

Palmer, Richard E. (2003) Hermeneutics, Intepretation Theory In Schleimacher, Dilthey,

Heideger, and Gadamer.Diterjemahkan oleh Musnur Hery dan Damanhuri Muhamad. Hermeneutika, Teori Baru Mengenai Interpretasi. Yogyakarta: Pustaka Pelajar
Puspositardjo, S. 2005. Seni Dalam Pendidikan. Kumpulan Makalah Seri Seni Pertunjukan Indonesia. Surakarta: Kerjasama PPS STSI \& The Ford Foundation.

Pramutama, R.M. 1999. Unsur Pendidikan Seksual Pada Srimpi Renggawati di Kraton

Yogyakarta. Laporan Penelitian, STSI Surakarta.

Purwadmadi \& Linaras A. 2015. Seni Pertunjukan Indonesia 4. Dokumentasi tari Klasik (Beksan Jebeng, Beksan Floret, Srimpi Nadheg Putri, Bedaya Tejanata). Yogyakarta: UPTD Taman Budaya.

Putraningsih, Titik. 2016. “R e l e v a n s i Nilai- Nilai Tari Bedhaya Bondhet dalam

Pendidikan Karakter". Imaji, Jurnal Seni Dan Pendidikan Seni 14 (2), 160-176

Sayuti, Suminto A. 2016. Budaya Dan Kerifan Lokal di Era Global: Pentingnya Pendidikan Bahsa Dan Sastra. Disampaikan pada Seminar Nasional "Bahasa, Sastra, dan Pemuda" yang diselenggarakan oleh Prodi Pendidikan Bahasa dan Sastra Indonesia FIP Universitas Trunojoyo, Madura; pada hari Kamis, tanggal 29 September 2016 Sumaryono, E. 1999. Hermeneutik, Sebuah Metode Filsafat. Yogyakarta: Kanisius.

Supriyanto. 2009. Busana Tari Bedaya Gaya Yogyakarta Sebuah Kajian Estetika. Agem 8 (1), 1-17.

Soedarsono. 1996. Indonesia Indah, Seni Tari Tradisional Indonesia. Jakarta:

Yayasan Harapan Kita/BP3TMII.

Suryobrongto, GBPH. 1981. Kawruh Joged Mataram. Yogyakarta: Dewan Ahli YayasanSiswa Among Beksa.

Wardhana, Wisnoe, RM. 1981. Tari Tunggal, Beksan Dan Tarian Sakral Gaya Yogyakarta. Dalam Mengenal Tari Klasik Gaya Yogyakarta, Wibowo Fred (Ed). Dewan Kesenian Propinsi DIY.

Widayanti, Sri. 2011. Tinjauan Filsafat Seni Terhadap Tata Rias dan Busana Pengantin Paes Ageng Kanigaran Gaya Yogyakarta. Jurnal Filsafat, 1,(3),240256. 


\section{Sumber Internet:}

Batik Larangan. Retrieved 15 Februari 2019

from https://www.kratonjogja.id/ kagungan-dalem/12/motif-batiklarangan. 